\title{
REFLEXÕES SOBRE DESAFIOS DE UM DIREITO COSMOPOLITA SUSTENTADO PELA SOLIDARIEDADE: A QUESTÃO DA VULNERABILIDADE NOS PARADIGMAS DAS MODERNIDADES SÓLIDA E LÍQUIDA
}

\author{
REFLECTIONS ABOUT CHALLENGES TO A COSMOPOLITAN LAW BASED ON SOLIDARITY: THE \\ VULNERABILTY ISSUE IN THE SOLID AND LIQUID MODERNITY PARADIGMS
}

Carla Pereira da Silva*

\begin{abstract}
Resumo:
O presente estudo realiza exercício filosófico de reflexão investigativa a respeito do Cosmopolitismo, considerando suas fundamentações na neutralidade da coexistência, na tolerância e na solidariedade da defesa do direito do outro a sua diferença. Partindo-se do modelo líquido-moderno - cujas considerações baseiam-se em teoria do sociológo Zygmunt Bauman - e considerando-o fortemente imbuída de elementos sólido-modernos, arquiteta-se conjuntura em que o individualismo sobrepuja às forças gregárias da humanidade. $\mathrm{O}$ intuito essencial dos apontamentos realizados admite-se, primeiramente, como a demonstração da dificuldade da sociedade humana em realizar compartilhamentos com a Diferença, com a Ambivalência, preconizando, em segundo lugar, a construção paulatina de uma convivência humana alicerçada na Solidariedade, ou seja, no Autocomprometimento. O Objetivo é um verdadeiro e efetivo Direito Cosmopolita como forma de superação da Situação de Vulnerabilidade em que são colocados os seres humanos neutralizados pela luta mercadológica cotidiano pela satisfação, quando inexistente a real felicidade.

Palavras-chave: Cosmopolitismo. Tolerância. Solidariedade. Ambivalência. Vulnerabilidade. Modernidade Sólida. Modernidade Líquida.
\end{abstract}

\begin{abstract}
:
The present study makes a philosophic exercise of investigative reflection about Cosmopolitism, considering its fondations: unprejudiced coexistence, tolerance and the solidarity in the defense of others' right to be different. Beginning with liquidmodernity model - whose considerations are based upon the sociologist Zygmunt Bauman's theory - and considering this model strongly filled with solid-modern elements, a scenario in which individualism surpasses the humanity social forces is built. The essential aims in the reflections made are known to be, firstly, the demonstration of the human society's difficulty in accomplishing stable relationships with Diversity and with Opposites, stimulating, secondly, the gradual construction of a human companionship based on Solidarity, in other words, Self-commitiment. The objetive is a true and effetive Cosmopolitan Law, as a way of surpassing the Vulnerability Situation of the human beings neutralized by routine's market battle for satisfaction, knowing that real happiness does not exist.
\end{abstract}

Keywords: Cosmopolitism. Tolerance. Solidarity. Vulnerability. Opposite Diversity. Solid-Modernity. Liquid-Modernity.

A autora é Graduanda na Faculdade de Direito da Universidade de São Paulo. E-mail: carla.psilva@uol.com.br. 
1. Introdução - intento de exercício filosófico

A filosofia permite e consente o abalo do que simplesmente aparece aos olhos como sendo a dimensão do dado, a experiência da evidência, ou como sendo a soma das impressões de vida extraída a partir de um conjunto de vivências. A filosofia, portanto, corresponde a uma atitude radical, perante a vida e perante o mundo. Onde há ordem, ela pode ver desordem, onde há desordem ela pode ver ordem. É desta subversão que acaba por colher o espírito de sua tarefa desafiadora, porque comprometida com a possibilidade do novo, do não visto, e não experimentado, do inovador, daquilo que desafia a ordem da regularidade dos fenômenos e da aceitação da tutela da vida desde fora. Ou seja, a filosofia acaba por consentir uma certa atitude perante o mundo, que potencializa sua capacidade transformadora, na medida em que des-aliena, por abalar a estrutura e refundar de sentido a experiência sobre o mundo.

A filosofia, como weltweisheit, como sabedoria mundana, como razão capaz de agir no mundo, significa um tipo de atitude perante o mundo fundadora de sentido. Em última análise, a filosofia nos impede de banalizar a vida, o mundo, a existência, as coisas, na medida em que seu exercício favorece um movimento de resistência racional diante de uma tendência, congênita à da sabedoria e à da busca pelo conhecimento, à simples aceitação das coisas como elas são, enquanto dados brutos que independem da reinvenção e do processo criativo do pensamento. É esta criatividade que confere ao filósofo a tarefa de ser extemporâneo. ${ }^{1}$

Considera-se, como pressuposto inexorável, a imensidão da complexidade envolvida na compreensão e, em maior grau, na harmonização da Convivência Humana, em decorrência, menciona-se de forma sucinta e essencial, da pluralidade e múltipla potencialidade envolvidas em seus componentes, agentes, gerando concomitantemente, forças de agregação e distanciamento intersubjetivo.

A adoção dos quadros paradigmáticos desenvolvidos por Zygmunt Bauman para a análise da questão do direito cosmopolita e de suas dificuldades de compreensão, delineamento e consolidação - questões de fundo relacionadas à própria forma como são entendidas e vivenciadas as relações entre os seres humanos - ocorre como um recurso sócio-filosófico de abordagem, mesmo que, no presente contexto, de forma genérica, de problemáticas profundas, apesar de sub-reptícias nas discussões hodiernas sobre o

BITTAR, Eduardo Carlos Bianca. Curso de filosofia política. 3. ed. São Paulo: Atlas, 2007. p. 5-6. 
desenvolvimento do espaço das interações humanas no campo internacional. Compreendese, a partir da referida perspectiva, que o direito cosmopolita é responsável pela suscitação de questões complexas e conjunturais, para a sinalização das quais serão utilizados os enquadramentos organizativos da Modernidade Sólida e da Modernidade Líquida ou PósModernidade, tratando apenas levemente esses elementos denominativos polêmicos, ${ }^{2}$ visto que não se tratam de questões de centro no presente estudo, mas sim de ferramentas para a análise da problemática da convivência humana e do cosmopolitismo.

Parte-se, no entanto, no presente estudo, do pressuposto de que há elementos peculiares e relevantes na sociedade hodierna, responsáveis em conjugação pela caracterização do modelo de grupamento humano como inóspito, injusto, agressivo, violento, considerando a perversidade com que funcionam seus mecanismos de manutenção. Esse enunciado, por meio de sua simplicidade, sintetiza a grave fragmentação observada e sentida na vida das pessoas. O nível de dissocialização culminante a partir desse complexo cenário é tamanho que provoca em segundo grau uma exorbitante descrença nas potencialidades da sociedade, nas buscas conjuntas, no compartilhamento, na ação coletiva, ao contrário, a felicidade existe, nessa perspectiva, apenas à medida que se excluem os demais. Vislumbrar o ser humano sua vida nesses moldes decorre da vulnerabilidade, da fragilidade, da impermanência e, acima de tudo, do caráter de pouca acessibilidade com que são compreendidos os caminhos socialmente propostos para a felicidade. $\mathrm{O}$ oferecimento insistente de protótipos compráveis de felicidade conjugado a uma competição excludente inelutável da maioria - os fracos sociais: seres altamente vulneráveis, consumidores débeis - distancia os seres humanos, que passam a pressupor a animalidade imediata de qualquer próximo. Enfim, é significativamente profunda a questão do Cosmopolitismo quando se consideram os alicerces e efeitos da existência humana hodiernamente - herança moderna -, considerando-se a dificuldade de convivência, em especial, em um contexto solidário cosmopolita, entendendo-se a felicidade em sua crescente impossibilidade. Dissociam-se felicidade e outra e associam-se aniquilação e satisfação, ou seja, prazer imediato, suspensão com a duração de um suspiro na repetição do trabalho cotidiano.

\footnotetext{
“(...) Talvez vivamos em uma era pós-moderna, talvez não. Mas de fato vivemos em uma era de tribos e tribalismo. É o tribalismo, miraculosamente renascido, que injeta espírito e vitalidade no louvor da comunidade, na aclamação de fazer parte, na apaixonada busca da tradição. Neste sentido, pelo menos, o longo desvio da modernidade levou-nos aonde nossos antepassados outrora principiaram. Ou assim talvez pareça.

O fim da modernidade? Não necessariamente. Sob outro aspecto, afinal, a modernidade está muito conosco. Está conosco na forma do mais definidor de seus traços definidores: o da esperança, a esperança de tornar as coisas melhores do que são - já que elas, até então, não são suficientemente boas" (BAUMAN, Zygmunt. $O$ mal-estar na pós-modernidade. Tradução de Mauro Gama e Cláudia Martinelli Gama. Rio de Janeiro: Jorge Zahar, 1998. p. 101).
} 
Esforços para manter à distância o "outro", o diferente, o estranho e o estrangeiro, e a decisão de evitar a necessidade de comunicação, negociação e compromisso mútuo, não são a única resposta concebível à incerteza existencial enraizada na nova fragilidade ou fluidez dos laços sociais. Essa decisão certamente se adapta à nossa preocupação contemporânea obsessiva com poluição e purificação, à nossa tendência de identificar o perigo para a segurança corporal com a invasão de "corpos estranhos" e de identificar a segurança nãoameaçada com a pureza. A atenção agudamente apreensiva às substâncias que entram no corpo pela boca e pelas narinas, e aos estranhos que se esgueiram sub-repticiamente pelas vizinhanças do corpo, acomodam-se lado a lado no mesmo quadro cognitivo. Ambas ativam um desejo de "expeli-los do sistema". ${ }^{3}$

Numa sociedade assim, a vulnerabilidade também é (ao menos potencialmente) universal. Sua universalidade, assim como a da tentação do estar à frente, à qual se relaciona intimamente, reflete a insolúvel contradição interna de uma sociedade que estabelece para todos os membros um padrão de felicidade que a maioria desses "todos" é incapaz ou impedida de alcançar. ${ }^{4}$

Diante do Cosmopolitismo, tomado como problemática histórico-social conforme intróito precedente, a função da Filosofia do Direito - entendida como perspectiva sobre o Direito incumbida da missão de abertura, de extravasamento em relação a um conjunto de regulações que, per si, sistema isolado, não é suficiente para compreender a complexidade dos fenômenos com os quais lida, uma vez que não trata do caminho, mas da linha de chegada jurídica - reconhece-se, exatamente, diante da observação descomprometida com rígidos moldes de sustentação, aquela de sobrepujar a pretensa obviedade da aparência, analisando através das vestes que se mostram comumente e alcançando as raízes mais profundas sobre o que se reflete, superando, enfim, o que convencionalmente se exige. A sociedade não é senão através da transdisciplinariedade, reconhecendo defeituosas abordagens fragmentárias de fenômenos sociais.

\section{Problematização}

Nossas vidas, quer o saibamos ou não e quer o saudemos ou lamentemos, são obras de arte. Para viver como exige a arte da vida, devemos, tal como qualquer outro

BAUMAN, Zygmunt. Modernidade líquida. Tradução de Plínio Dentzien. Rio de Janeiro: Jorge Zahar, 2001. p 125.

4 Id. A arte da vida. Tradução de Carlos Alberto Medeiros. Rio de Janeiro: Jorge Zahar, 2009. p. 38. 
tipo de artista, estabelecer desafios que são (pelo menos no momento em que estabelecidos) difíceis de confrontar diretamente; devemos escolher alvos que estão (ao menos no momento da escolha) muito além de nosso alcance, e padrões de excelência que, de modo perturbador, parecem permanecer teimosamente muito acima de nossa capacidade (pelo menos a já atingida) de harmonizar com o que quer que estejamos ou possamos estar fazendo. Precisamos tentar o impossível. E, sem o apoio de um prognóstico favorável fidedigno (que dirá da certeza), só podemos esperar que, com longo e penoso esforço, sejamos capazes de algum dia alcançar esses padrões e atingir esses alvos, e assim mostrar que estamos à altura do desafio.

A incerteza é o hábitat natural da vida humana, ainda que a esperança de escapar da incerteza seja o motor das atividades humanas. Escapar da incerteza é um ingrediente fundamental, mesmo que apenas tacitamente presumido, de todas e quaisquer imagens compósitas da felicidade. É por isso que a felicidade "genuína, adequada e total" sempre parece residir em algum lugar à frente: tal como o horizonte, que recua quando se tenta chegar mais perto dele". 5

A sociedade conta, como parte de sua composição e funcionamento, com instrumentos vulníficos, responsáveis pela geração dos elementos formadores da grande órbita em torno da qual transladam os elementos da questão da organização social tal como a temos. O fenômeno brutal da utilização dos instrumentos penais para a aniquilação do outro, como ser diferente e vulnerável a exercícios autoritários da uniformização dos submetidos, tem relação com a demanda hodierna por uma maior consciência comprometida e atuante da dignidade da pessoa humana, existente apenas quando incondicionada por modelos de comportamento esmagadores através da punição, elucidando seu reconhecimento como forma irrenunciável de fortalecimento de uma identidade comum entre os seres humanos, ou seja, como um fator de coordenação da convivência. Por conseguinte, o desenvolvimento contínuo do autoconhecimento humano é expresso na razão jurídica, por meio da noção de dignificação da pessoa humana como valor com o qual funciona o maquinário jurídico. ${ }^{6}$

O que se pretende sinalizar através do presente trabalho - fundamentalmente, apesar da simplicidade, um exercício filosófico de questionamento do explícito - é a relação entre os conjuntos de questões apontados sinteticamente como: complexidade do caminhar em direção à implementação de um efetivo parâmetro cosmopolita de regulação; insistência social na construção de categorias de inadequados, arrivistas, excluídos, párias,

BAUMAN, Zygmunt. A arte da vida. Tradução de Carlos Alberto Medeiros. Rio de Janeiro: Jorge Zahar, 2009. p. 31.

6 "A razão jurídica se resolve em uma determinada condição humana em que cada indivíduo é, para a humanidade, o que uma hora é para o tempo: parte universal e concreta do todo indissolúvel" (FELIPPE, Marcio Sotello. Razão jurídica e dignidade humana. São Paulo: Max Limonad, 1996. p. 100). 
vagabundos, dentre outros, enfim, vulneráveis, pois, na realidade, perigosos para o sucesso do escamoteamento de temidos demônios interiores de indagação do posto; a intransigência em relação ao diferente combinada com a busca pela segurança, em detrimento de construções conjuntas da pluralidade, procura esta realizada, por meio da sociedade sólidomoderna ou comunidade líquido-moderna; padronização calcada no traçado de fórmulas de subordinação reforçada através de jogos sociais ilusórios cujo resultado consiste na afirmação da culpabilidade do indivíduo em relação à sua situação, o que, na realidade, reforça a idéia de $Z$. Bauman de que um dos problemas mais inflamados na modernidade líquida consiste na fragmentação das soluções às questões sociais, como se exclusivamente individuais fossem, como se grudados na personalidade dos inválidos estivessem, fazendoas adentrar no campo da incriminação desses problemas coletivamente produzidos.

A problemática da lida com a ambivalência relaciona-se, por conseguinte, intimamente, com a questão do direito cosmopolita, já que, enquanto não forem discutidas as insanas polarizações sobre as quais se baseiam as sociedades e nas quais se pretendem fundamentar as comunidades, não será passível de construção o verdadeiro Direito Cosmopolita, que se sabe aquele alicerçado na Solidariedade para com a Ambivalência, responsável por agregar as diferenças em torno da Atuação Política.

Menciona-se, por fim, que, de forma alguma, os diagnósticos em relação aos tempos sólido-modernos ou líquido-modernos são seguidos por uma aprovação ou reprovação plenas, ou seja, os quadros paradigmáticos e suas caracterizações são utilizados com o intuito exatamente de perceber as profundezas das questões, muitas vezes, recorrentes e, em decorrência, apenas superficialmente analisadas. Realizar-seá uma comparação entre dois momentos que muito possuem um do outro, apontando, portanto, elementos compartilhados, auxiliadores da compreensão das estruturas e das possíveis diretrizes da problemática do direito cosmopolita em linhas gerais, respeitadas as restrições deste trabalho.

3. Apontamento da relação entre o Direito Cosmopolita e a dificuldade da convivência com o outro - questão de fundo: objetivo

Com o ocaso do sol universal, escreveu o estudante Karl Marx, as mariposas reúnem-se junto à lâmpada doméstica. Com o secamento do artificial e sofisticado lago da universalidade, os putrescentes pântanos de provincialismo do passado recente cintilam convidativos, como os refúgios naturais para todos os que precisam nadar em segurança. Basta de salvação pela sociedade - mas talvez a comunidade torne a salvação desnecessária? "Não devemos procurar ganchos suspensos no céu, mas somente apoios para as pontas dos pés" é como Richard Roty resume a disposição 
de ânimo dos despojados, e passa a elogiar o etnocentrismo e a advertir-nos para, em vez de desperdiçarmos nosso tempo na busca vã para objetividade e pontos de vista universais, concentrarmo-nos nas perguntas: "Com que comunidades você deve identificar-se?" e "O que devo fazer com o meu isolamento? ${ }^{7}$

A miscifilia bem pode ser substituída pela miscifobia; a tolerância da diferença bem pode ser aliada à categórica recusa da solidariedade; o discurso monológico, em vez de dar lugar a um discurso dialógico, cindir-se-á em uma série de solilóquios, com os falantes não mais insistindo em ser ouvidos, mas se recusando também a escutar. ${ }^{8}$

O que Representa o Direito Cosmopolita - Perspectiva Adotada

O Direito Cosmopolita é responsável por alçar ao papel protagonista uma das questões estruturais mais amalgâmicas da convivência humana, em especial, quando da compreensão de seu sentido por meio da chave histórica de pensamento, capaz de revelar elementos ocultos aos mecanismos automáticos do cotidiano: a existência de fortes categorias - reiteradamente utilizadas e impregnadas à face em função da persistente apropriação que delas fazemos - entre nós e o Outro na coexistência, em outras palavras, discussões acerca do direito cosmopolita nos conduzem a um caminho de volta aos momentos em que o gênero humano optou por desprezar sua condição de gênero e seus elementos de identificação, reconhecendo exclusivamente a tutela de idiossincrasias extremas, e dificultar a percepção das semelhanças, através da criação de instrumentos de organização fragmentários. O Direito cosmopolita demonstra o esforço pela construção de canais de comunicação entre os seres humanos que, historicamente, lutaram pela inviolabilidade de suas armaduras protetoras, de seus instrumentos de escamoteação da necessidade de solução de questões de base, iludindo-se com a possibilidade de segurança por meio de uma atitude de indiferença negligente - atitude já quase componente da quintessência do existir humano.

O Direito Cosmopolita, em suas raízes mais nucleares, constitui-se, na realidade, em um conjunto de instrumentos que intentam estimular a aceitação comprometida com a preservação da Ambivalência, observando sem escândalo a existência real de dois aspectos radicalmente distintos e possivelmente antagônicos, mas conviventes. As mencionadas raízes podem ser compreendidas como apontamentos

BAUMAN, Zygmunt. O mal-estar na pós-modernidade. Tradução de Mauro Gama e Cláudia Martinelli Gama. Rio de Janeiro: Jorge Zahar, 1998. p. 100

8 Id. Ibid., p. 103 
gerais do que efetivamente está envolvido nas reflexões sobre o direito cosmopolita, mesmo previamente à contemporaneidade, quando as noções de tolerância e solidariedade formam uma concepção conjunta de objetivo, intuito basilar de evolução a partir de uma simples identificação do diferente, fase-primeira de uma estruturação efetivamente sólida de direito dirigido ao gênero humano, à humanidade auto-reconhecida e estimulada. Afirma-se tal elemento, pois formulações precedentes à abordagem da solidariedade, desconsiderando a necessidade de superação da simples aceitação ou tolerância negligenciam a irrenunciabilidade desse grau de reciprocidade como pressuposto de um verdadeiro cosmopolitismo. É a concepção de cosmopolitismo que penetra as camadas grupais e coletivamente aceitas em decorrência da generalidade reconhecível e atinge o indivíduo em uma operação - compreendida no estágio de construção atual ainda como esquizofrênica - de identificação humana por trás das máscaras da convivência e da compreensão das inexoráveis ambivalências própria e alheia. A ambição de agregação revelada por menções ao direito cosmopolita anteriores às realizadas na conjuntura atual sabe-se de menor grau em função das condicionantes das épocas em que foram efetuadas, cuja internacionalidade da proteção dos direitos humanos ainda era sabida como nula ou bastante incipiente.

$\mathrm{Na}$ expressão de Immanuel Kant - conhecido como o grande propulsor da concepção cosmopolita na Era Moderna -, o Direito Cosmopolita reconhece-se obrigatoriamente como um dos pressupostos para a configuração real da paz perpétua ${ }^{9}$ - presente como componente fundamental definitiva da constituição dos Estados na condição de paz propugnada -, salientando sua conceituação como um direito público da humanidade em geral. Por maiores as distinções entre os momentos históricos setecentista em que refletia Kant e o hodierno, o direito cosmopolita sabe-se um conjunto de normas direcionado a uma sociedade-mundo e ocupando-se de cidadãos-mundo, cujo resguardo considerava-se à época como responsabilidade de Estados-nação, forçados ao reconhecimento e à tutela do gênero humano, independentemente de sua procedência, como condições de consolidação e preservação da convivência pacífica no mundo.

Como complementação, o referido doutrinador alemão menciona o Direito à Hospitalidade Universal como elemento ao qual se limita o direito cosmopolita por ele propugnado, compreendendo-o em duas facetas: de um lado, o direito basilar do estrangeiro

\footnotetext{
9 "Ora, como se avançou tanto no estabelecimento de uma comunidade (mais ou menos estreita) entre os povos da Terra que a violação do direito num lugar da Terra se sente em todos os outros, a idéia de um direito cosmopolita não é nenhuma representação fantástica e extravagante do direito, mas um complemento necessário de código não escrito, tanto do direito político como do direito das gentes [direito internacional], num direito público da humanidade em geral e, assim, um complemento da paz perpétua, em cuja contínua aproximação é possível encontrar-se só sob esta condição". (Kant, Immanuel. À paz perpétua e outros opúsculos. Tradução de Artur Mourão. Rio de Janeiro: Edições 70, 1990. p. 140).
} 
- definido em contraposição ao nacional, vinculado à questão jurídica da nacionalidade e da detenção, portanto, de direito e obrigações perante uma organização política estatal - de não ser tratado com hostilidade, em outras palavras, assentamento da pretensão do grupo mencionado de que a ele não seja dirigida provocação, agressividade, não sendo tomado ou convertido como / em inimigo; do outro lado, o dever do Estado de não violar, fraudar violentamente a hospitalidade oferecida pela população de outro Estado, impedindo, dessa forma, a construção de um cenário de conquista e hostilidade internacional. Em síntese, por conseguinte, o direito cosmopolita kantiano consistia, considerando o incipiente estágio de desenvolvimento inclusive do direito internacional - conjunto de normas de simples coexistência entre os Estados -, em uma arquitetagem responsável por sugestionar a necessidade e uma modelagem estrutural possível de relacionamento pacífico entre seres humanos inseridos em diferentes organizações políticas soberanas - Estados - intentando sobrepujar uma rigidez insustentável do internacionalmente desequilibrado tripé povoterritório-soberania.

I. Kant foi responsável pela preconização do cosmopolitismo relacionado como condição de paz mundial em seus alicerces fundamentais, quando situado em um momento histórico no qual nem mesmo a Federação de Estados, pressuposto do Direito Internacional kantiano, era possível, considerando ainda bastante sólida a categoria da soberania estatal e a relação interestatal se resumia à simples configuração de formas de coexistência, ou seja, o direito internacional tratava de questões de fronteira em um contexto de beligerância regular e contato como decorrente da impreterível proximidade geográfica ou necessidade econômica. O referido pensador era desprovido, portanto, das referências hodiernas de perda da sustentação hegemônica e da concepção estanque dos mecanismos tradicionais de Estado, do poder absoluto, soberania como plena capacidade de autodeterminação e gestão, de controle total, decorrentes de novas demandas por um ambiente internacional mais solidário, dotado, de bases humanitárias mais fortalecidas e, por conseguinte, a lida com questões transnacionais, com a transformação dos direitos humanos, como nicho exclusivamente jurídico-formalista, atrelado a concepções de Estado nacional, em instrumento de regulação dos cidadãos do mundo, dos seres humanos como gênero, tornando a diferença passível de união.

$\mathrm{Na}$ hodiernidade, reconhece-se o Direito Internacional dos Direitos Humanos como um passo antecedente na efetiva construção de um Direito Cosmopolita, transcendente como fundamento das divisões geopolíticas mundiais, já que calcada na construção de pontes diretas entre os seres humanos. A ânsia pela superação de categorias opressoras do passado sólido-moderno e a criação conjunta de alternativas, de novos quadros, nesse momento de transição paradigmática, sinaliza exatamente os fundamentos das demandas líquido-modernas pela construção de canais de comunicação e atuação dialógicos conscientes de que "nenhum dos extremos na concepção da política permitirá 
a agregação dos valores da comunidade internacional, e muito menos a integração das concepções de direitos humanos". ${ }^{10}$

Modernidade sólida e modernidade líquida - caracterizações

A opção pela abordagem sócio-filosófica de Zygmunt Bauman, como já mencionado em contornos bastante genéricos, culmina no estudo dos quadros conjunturais - paradigmas - da Modernidade Sólida e da Modernidade Líquida, conjuntos de categorias para os quais há implicações relevantes ao entendimento das formas de convivência social. Expor-se-ão os elementos dotados de maior essencialidade para a questão da repercussão da compreensão do Outro na arquitetagem do Direito Cosmopolita:

Socialmente, a modernidade trata de padrões, esperança e culpa. Padrões - que acenam, fascinam ou incitam, mas sempre se estendendo, sempre um ou dois passos à frente dos perseguidores, sempre avançando adiante apenas um pouquinho mais rápido do que os que lhes vão no encalço (...) mesclando a esperança de alcançar a terra prometida com a culpa de não caminhar suficientemente depressa. A culpa protege a esperança da frustração; a esperança cuida para que a culpa nunca estanque. ${ }^{11}$

Questões que envolvem a azáfama da diferença, com a pluralidade, envolvem, no tocante à Modernidade sólida, a árdua responsabilidade da construção da identidade, que, por sua vez, relaciona-se à uma síndrome crônica do nunca, da insaciedade, das projeções. O diagnóstico de Z. Bauman conduz à associação, na inflexibilidade da etapa sólido-moderna, entre horror à ambivalência e luta incessante contra $\mathrm{O}$ Diferente, considerado como violação materializada do padrão eleito como soberano. Havia um caminho construído para ser seguido, há uma ilusão de propósito comum, racionalmente estruturado em uma perfeição, portanto, inquestionável responsável por gerar um medo insano do desabrigo, da exclusão. A modernidade em sua versão sólida preconizava a existência de um padrão humano universal, um molde no qual se deveriam basear as escolhas de cada indivíduo, já que a alteridade em sua contaminada repulsividade é considerada inconveniente irracional momentâneo, diante da peregrinação em direção à felicidade segura dos marcos civilizatórios. A autenticidade, a consciência do próprio ser e de sua contingência são tomadas por insanidade; não deve haver dúvidas, caminhamos todos juntos, sempre para frente e na mesma direção.

\footnotetext{
10 BITTAR, Eduardo Carlos Bianca. O direito na pós-modernidade. Rio de Janeiro: Forense, Universitária, 2005. p. 351.

11 BAUMAN, Zygmunt. O mal-estar na pós-modernidade... cit., p. 91.
} 
A solidariedade ou mesmo a mera tolerância para com os impuros, os estranhos em direção aos quais convergem todos os medos coletivos de revolução da ordem, são compreendidas como subversão, como indicativo de inadequação, portanto, a simples ameaça conhecida do isolamento, da solidão, reprime a peculiaridade, erguendo fronteiras rudes entre o permitido e o proibido, o aceito e o condenado. A padronização em diversos dos aspectos determinantes da vida moderna é responsável pela reiteração da angústia em relação à ambivalência e, por conseguinte e concomitantemente, do agigantamento de uma severa paixão pelo problema da diferença, oposto do que se compreende hoje como condição humana: a neutralização do que instiga e confere sentido à própria existência do ser político, da convivência. A diferença é compreendida como ofensa em si mesma.

As idéias sustentadoras do mundo moderno eram elementos sólidos, rígidos, pensavam-se eternos; declarou a sociedade guerra ao paroquialismo, com a consolidação das concepções propugnadas através das Revoluções do fim do século XVIII e início do XIX - conjugação de Estado, comunidade, identidade e emancipação em um imenso projeto estrutural de planejamento social - universalizava-se progressivamente a condição humana em uma renovação insistente por meio de constantes destruições criativas. A vida sólido-moderna é calculadamente experenciada em processos de adaptações, autoobliterações, desapoderamentos ${ }^{12}$ da própria diferença: “(...) os estranhos modernos tinham a marca do gado da aniquilação, e serviam como marcas divisórias para a fronteira em progressão da ordem a ser constituída (...)". ${ }^{13}$ Afinal, complementa-se afirmando que todas as características sinalizadas geram um conjunto de elementos congregados em função de um mesmo empreendimento: o planejamento, o cálculo das fases do processo de educação, organização dos povos associado à substituição das comunidades locais pelos alicerces artificiais, juridicamente sustentados, do Estado e da nação. As escolhas já tinham sido realizadas pelo Estado ao indivíduo, sendo elas sempre classificadas pela palavra Renúncia do Presente para Construção de um Futuro, adquirindo segurança.

$\mathrm{Na}$ conjuntura da Modernidade-líquida “o que a modernidade se pôs a destruir tem o seu dia de doce vingança", ${ }^{14}$ os problemas relacionados ao diferente, ao Outro modificaram suas máscaras, no entanto, explicitam, alcançando da mesma forma, a questão profunda da convivência humana: a dificuldade da autodefinição individual vinculada ao dimensionamento do gênero humano, as comunidades, ou melhor, as

\footnotetext{
12 A questão do Desapoderamento consiste na auto-anulação, na autodestruição e, em especial, na modernidade líquida, na alienação da própria identidade aos desígnios mercadológicos, perdendo o próprio subjetivismo para a adequação a padrões, mais ou menos dinâmicos de reconhecimento e/ou destacamento social. Bauman preconiza em sua obra Vida para Consumo uma luta pelo Reapoderamento dos sujeitos, fenômeno que, segundo ele, tornaria a convivência mais sincera e aliviaria as tensões imiscuídas na simples adequação social pelo conforto em detrimento da consciência solidária de si mesmo e da diferença alheia.

13 BAUMAN, Zygmunt. O mal-estar na pós-modernidade... cit., p. 43.

14 Id. Ibid., p. 101.
} 
Neotribos, passaram a ser veículos de identificação e felicidade pessoais, assim como o era a civilização sólido-moderna.

Equivoca-se a visão que associa impreterível aumento da solidariedade ou, ao menos, da tolerância e os processos hodiernos de multiplicação de oportunidades, de ampliação da quantidade - não necessariamente a qualidade - de informações, da aguda pluralização dos parâmetros de comparação, com o enfraquecimento dos grupos de referência, menos auto-evidentes, da existência, portanto, de modelos e comandos conflitantes "de tal forma que todos e cada um foram desprovidos de boa parte de seus poderes de coercitivamente compelir e restringir". ${ }^{15}$ A modernidade líquida é vislumbrada porZ. Bauman em sua mais crua ambivalência, e, portanto, dotada de potencialidade opostas, cuja manifestação dependerá da direção dos esforços realizados. ${ }^{16}$ A desregulamentação, a privatização - a apatia política e a invasão de questões privadas a espaços públicos não diminuem a violência pelo genocídio pavoroso da purificação do diferente, o outro, do estrangeiro, do responsável por explicitar as ilusões da ordem social opressora, quando, como mencionado, são arquitetadas estratégias de solução nos termos neotribais, da aceitação do isolamento, da segregação e de significativa cessão da própria autonomia, transformada em liberdade de escolha no mercado de consumo.

Não admira que a pós-modernidade, a idade da contingência für sich [por si], da contingência consciente, seja também a idade da comunidade: da ânsia pela comunidade, da busca, invenção e imaginação da comunidade. O pesadelo dos nossos contemporâneos, escreve Manning Nash, "é ser desenraizado, ficar sem documentos, sem Estado, sozinho, alienado e à deriva num mundo de organizados outros", de ter, em outras palavras, negada uma identidade por aqueles que, sendo outros (isto é, diferente de nós), sempre parecem a distância "organizados" e seguros da própria identidade (...). “A dimensão étnica da identidade (...) reside no fato de que os integrantes dos grupos étnicos são vistos uns pelos outros como "humanos" e confiáveis de um modo que os forasteiros não o são. O grupo étnico fornece refúgio contra um mundo hostil, de desprezo". A comunidade - étnica,

15 BAUMAN, Zygmunt. O mal-estar na pós-modernidade... cit., p. 14.

16 Esforços para manter à distância o "outro", o diferente, o estranho e o estrangeiro, e a decisão de evitar a necessidade de comunicação, negociação e compromisso mútuo, não são a única resposta concebível à incerteza existencial enraizada na nova fragilidade ou fluidez dos laços sociais. Essa decisão certamente se adapta à nossa preocupação contemporânea obsessiva com poluição e purificação, à nossa tendência de identificar o perigo para a segurança corporal com a invasão de "corpos estranhos" e de identificar a segurança não-ameaçada com a pureza. A atenção agudamente apreensiva às substâncias que entram no corpo pela boca e pelas narinas, e aos estranhos que se esgueiram sub-repticiamente pelas vizinhanças do corpo, acomodamse lado a lado no mesmo quadro cognitivo. Ambas ativam um desejo de "expeli-los do sistema". (BAUMAN, Zygmunt. Modernidade líquida. Tradução de Plínio Dentzien. Rio de Janeiro: Jorge Zahar, 2001. p. 125) 
religiosa, política ou de outro tipo - é vista como uma mistura incomum de diferença e companhia, como singularidade que não é retribuída com a solidão, como contingência com raízes, liberdade dotada de certeza; sua imagem e sedução são tão incongruentes como aquele mundo de ambivalência universal contra o qual - espera-se - forneceria abrigo. ${ }^{17}$

O choque paradigmático líquido-moderno associado com uma imensa perda dos referenciais universais, duros, impassíveis de visualização do mundo e determinação do papel pessoal na sociedade e no traçado da própria vida conduzem a uma sensação, muitas vezes, desesperadora de insegurança, abrindo espaço tais lacunas para o entranhamento da lógica do mercado na confecção do existir humano, ampliando estrondosamente a legitimidade social dos valores decorrentes da comodificação - processo de transformação do ser humano em mercadoria adequada a um nicho do mercado, recebendo um certificado de reconhecimento e aprovação públicos resultando em um bem-estar, um conforto da admiração da coletividade; abdicação da própria subjetividade em benefício de uma efêmera conciliação com algum porto seguro.

Nos termos de Z. Bauman na obra A Arte da Vida, há, na hodiernidade, uma impressionante convicção de que a infelicidade não pode ser real, ou melhor, genuína, uma vez que existe a possibilidade de se adquirir um novo eu feito sob encomenda gerando uma situação que, embora imbuída de quase nenhuma carga de autenticidade, seguem o padrão da relação entre comprador e mercadoria e, portanto, caracterizadas pela instabilidade, pela impermanência, pela fragilidade, em uma conjuntura de Compromissofobia: fazse do transitório a regra e da permanência, exceção, ${ }^{18}$ quaisquer instrumentos de fuga, conseqüentemente, são inócuos no aumento da segurança, minimizando o medo e a angústia como características essenciais do homem contemporâneo.

Os apontamentos realizados até o presente momento culminam na apresentação explícita da questão do multiculturalismo, amplamente preconizado como ferramenta fundamental na superação dos obstáculos da convivência na hodiernidade. Inicia-se com a reflexão de que a comunidade confere a sensação, especialmente no mundo líquido, fluido, de conforto, aconchego, já que agita em cada ser humano as moléculas da saudade do ventre materno: "É como um teto sob o qual nos abrigamos da

17 BAUMAN, Zygmunt. Modernidade e ambivalência. Tradução de Marcus Penchel. Rio de Janeiro: Jorge Zahar, 1999. p. 261.

18 “(...) uma firma americana altamente bem-sucedida, a Flexpetz, se preparava para abrir em outubro de 2007 uma filial londrina que "possibilitará aos clientes gastarem apenas algumas horas, ou alguns dias" com um de seus cães criados para aluguel, "amáveis e plenamente treinados" A Flexpetz é uma das empresas, que se multiplicam rapidamente, especializadas em "serviços que oferecem prazeres tradicionais sem o incômodo da propriedade". (BAUMAN, Zygmunt. A arte da vida. Tradução de Carlos Alberto Medeiros. Rio de Janeiro: Jorge Zahar, 2009. p. 26). 
chuva pesada, como uma lareira diante da qual esquentamos as mãos num dia gelado. (...) na comunidade podemos relaxar - estamos seguros, não há perigos ocultos em cantos escuros (com certeza, dificilmente um "canto" aqui é "escuro"). Numa comunidade, todos nos entendemos bem, podemos confiar no que ouvimos, estamos seguros a maior parte do tempo e raramente ficamos desconcertados ou somos surpreendidos. Nunca somos estranhos entre nós". ${ }^{19}$ Seguindo o raciocínio, diz-se que o exorbitante fascínio que exerce a concepção dessa comunidade, elemento que sempre esteve além do que os seres humanos poderiam alcançar, como uma esperança da experimentação do paraíso perdido, alimenta-se do poder da imaginação humana, instrumento da existência humana que não é capaz de mensurar per si os implicadores de um sonho de plenitude de segurança e liberdade concomitantes, deve-se reconhecer a complexidade da harmonização dos dois mencionados valores, cuja configuração conciliatória colabora ou dificulta a direção humana ao projeto do direito da humanidade como gênero. A busca pelo reconhecimento individual associado à descrença nos instrumentos sociais de diálogo e negociação - apatia política - gerando uma busca desenfreada pelo multicomunitarismo como sinonímia de um multiculturalismo intolerante, já que preconiza grupos hermeticamente fechados, tomam a cultura, em grandes linhas, como "fortaleza sitiada, os habitantes têm que manifestar diariamente sua lealdade inquebrantável e abster-se de quaisquer relações cordiais com estranhos. A "defesa da comunidade" tem que ter precedência sobre todos os outros compromissos". ${ }^{20}$

Tomando-se a universalidade da cidadania implicada na realização do direito cosmopolita como condição preliminar de enfrentamento do desengajamento como nova estratégia das relações de poder - responsável pelo abandono dos oprimidos à sua própria sorte - e da manipulação do excesso como substitutivo da verdadeira regulação social, por meio de políticas e atitudes individuais efetivas de reconhecimento solidário.

(...) uma coletividade que pretende ser a comunidade
encarnada, o sonho realizado, e (em nome de todo o bem
que se supõe que essa comunidade oferece) exige lealdade
incondicional e trata tudo o que ficar aquém de tal lealdade
como um ato de imperdoável traição. A "comunidade
realmente existente", se nos achássemos a seu alcance,
exigiria rigorosa obediência em troca dos serviços que
presta ou promete prestar. Você quer segurança? Abra
mão de sua liberdade, ou pelo menos de boa parte dela.
Você quer poder confiar? Não confie em ninguém de fora
da comunidade. Você quer entendimento mútuo? Não fale

19 BAUMAN, Zygmunt. Comunidade: a lusca por segurança no mundo atual. Tradução de Plínio Dentzien. Rio de Janeiro: Jorge Zahar, 2003. p. 8.

20 Id. Ibid., p. 127. 
com estranhos, nem fale línguas estrangeiras. Você quer essa sensação aconchegante de lar? Ponha alarmes em sua porta e câmeras de Tevê no acesso. Você quer proteção? Não acolha estranhos e abstenha-se de agir de modo esquisito ou de ter pensamentos bizarros. Você quer aconchego? Não chegue perto da janela, e jamais a abra. O nó da questão é que se você seguir esse conselho e mantiver as janelas fechadas, o ambiente logo ficará abafado e, no limite, opressivo. ${ }^{21}$

O resultado das observações realizadas no tocante à liquefação dos sólidos modernos constitui-se, sucintamente apontado, na "desabilitação" social, na incapacidade de identificação entre seres humanos de carne e osso - não-virtuais -, fenômeno que, em última instância, promove um aumento exorbitante de estranhos, inimigos, pois o cenário demonstra quase que uma perda da habilidade de manipulação da linguagem. A sociedade de consumo, por meio do profundo processo de comodificação - mercadorização do subjetivismo humano -, culmina em constrangimentos insistentes com as reações de outros seres humanos nos diálogos, uma vez que se deve considerar a imprescindibilidade de um mínimo dimensionamento do outro físico, em sua subjetividade atuante, para o estabelecimento bem-sucedido da comunicação. O neotribalismo associado ao lema "Consumo, Logo existo" caracteriza-se por uma existência frágil e dotada de pouco poder de cooptação ou banimento, viabilizada exclusivamente pelas decisões individuais de exibição dos símbolos de reconhecimento tribal.

A crueldade desse novo modelo social controlado por turistas manifestase através do silenciamento silencioso resultante da absorção privatista da vida pelo mercado, ou seja, esse processo compreende a internalização das forças contrárias a seu funcionamento por meio da estratégia da ilusória infinidade de escolhas. Os turistas, nos termos de Z. Bauman, são a epítome da evitação da identidade como elemento fixo, estável, comprometedor, sendo aqueles que, na fluidez da atual modernidade, possuem o controle situacional, pois estão dentro e fora de todos os lugares ao mesmo tempo, podendo experimentar presentes prazerosos, através de uma "bolha de osmose firmemente controlada". 22

Quer-se concluir afirmando que, enquanto o sistema social reproduzir a concepção de divisão dos seres humanos em vítimas e heróis, não será viável a construção séria de um direito cosmopolita real, já que impossibilitadas conversações igualitárias, solidárias entre subalternos.

${ }_{21}$ BAUMAN, Zygmunt. Comunidade: a lusca por segurança no mundo atual. Tradução de Plínio Dentzien. Rio de Janeiro: Jorge Zahar, 2003. p. 9-10.

22 Id. O mal-estar na pós-modernidade. Tradução de Mauro Gama e Cláudia Martinelli Gama. Rio de Janeiro: Jorge Zahar, 1998. p. 114. 
3. Ambivalência como inexorável pressuposto da convivência

No decorrer da longa, tortuosa e intrincada marcha da modernidade, devíamos ter aprendido a nossa lição: que o transe existencial humano é incuravelmente ambivalente, que o bem está sempre combinado com o mal, que é impossível traçar com segurança a linha entre a dose benigna e a venenosa de um remédio para as nossas imperfeições. ${ }^{23}$

É preciso também respeitá-los - e respeitá-los precisamente na sua alteridade, nas suas preferências, no seu direito de ter preferências. É preciso honrar a alteridade do outro, a estranheza do estranho, lembrando - com Edmond Jabès - que o "único é universal", que ser diferente é que nos faz semelhantes uns aos outros e que só posso respeitar a minha própria diferença respeitando a diferença do outro (...). ${ }^{24}$

Coletividades e a vulnerabilização da ambivalência - não ao cosmopolitismo

Deve-se iniciar indagando sobre como escapar daquilo que somos nós seres humanos coletivos e individuais, do que é você e do que sou eu? Como sobrepujar a humanidade em nós, pressuposta na diferença que nos identifica em sua existência? A utilização dos paradigmas da modernidade sólida e da modernidade líquida é responsável pela colocação da questão sobre o que fazermos de nós mesmos, onde encontrar a beleza de um porto seguro quando os sustentáculos sobre os quais nossos antepassados e educadores construíram suas instituições e seus planos - sintetizados na obsessão da necessidade da certeza em relação ao parâmetro seguido - e nos ensinaram a estar no mundo, já não nos perseguem com tamanha alucinação como quando do alicerçamento da civilização moderna. Comunidade, identidade, emancipação, tempo e espaço, idéiaschave na arquitetagem do mundo sólido-moderno alcançam, hodiernamente, status de contingência, sendo continuamente reestruturados e assumindo uma tal dinamicidade impensável quando de sua formulação primeira.

Concomitantemente à constatação da insuficiência dos moldes sobre os quais foi construída a realidade atualmente herdada, existe perturbação ambivalente de uma busca frenética por soluções que reiteram os caminhos disfuncionais sólido-modernos - dotados de configurações distintas, no entanto, semelhantes em suas estruturações profundas. A grave e complexa questão da comunidade na hodiernidade, como ilustração

\footnotetext{
23 BAUMAN, Zygmunt. O mal-estar na pós-modernidade. Tradução de Mauro Gama e Cláudia Martinelli Gama. Rio de Janeiro: Jorge Zahar, 1998. p. 104.

24 Id. Modernidade e ambivalência... cit., p. 249.
} 
de um dos aspectos do imenso processo de transformação pela liquefação e de cujas implicações no caminhar ao direito cosmopolita sabem-se significativas, fora apontada no item precedente do presente trabalho: problemática que consiste em um direito cosmopolita assentado, antagonicamente ao que propugna sua proposta de agregação, sobre concepções neotribalistas ou etnocentristas, construídas ambas nos moldes de comunidades estéticas, ${ }^{25}$ comunidades guarda-roupa ${ }^{26}$ ou comunidades ad hoc, fantasmas, carnavalescas, guarda casacos. $^{27}$

É importante reconhecer, juntamente com Z. Bauman, que questões relacionadas à delimitação de coletividades - sociedades, comunidades, ambas em suas inúmeras configurações -, como própria razão de ser, envolvem estabelecimento de fronteiras entre a loucura e a sanidade, o certo e o errado, limites que, certamente, não são absolutos, representando significados compartilhados, maciçamente aceitos por acordos tácitos de reiteração de condutas conformes, alinhadas ou mesmo não-contrárias, fenômeno que culmina na dignificação dessas formas conjuntas de viver no mundo: “Loucos são apenas os significados não compartilhados. A loucura não é loucura quando compartilhada" ${ }^{28}$ A submissão à sociedade na época moderna e a incansável busca por uma identificação comunitária na líquida-modernidade, apesar de auto-revelar-se como tal, não podem ser compreendidas como empreendimentos imprescindíveis para uma experiência libertadora, pois o que ocorre, na realidade, é o exorcismo do espectro das discussões de base, colocando como padrões inquestionáveis quaisquer dados que associem indivíduo à sociedade.

25 COMUNIDADES ESTÉTICAS - Conceito kantiano que designa uma comunidade limitada apenas a uma promessa, a uma esperança de unanimidade destinada a não ser pela própria impossibilidade de tal intento, o que não impede que a busca por sua implantação mantenha-se firme, em outras palavras, que alimente sua existência.

26 "(...) crescente demanda pelo que poderíamos chamar de "comunidades guarda-roupa" -invocadas a existirem, ainda que apenas na aparência, por pendurarem os problemas individuais, como fazem os freqüentadores de teatros, numa sala. Qualquer evento espetacular ou escandaloso pode se tornar um pretexto para fazê-lo (...). As comunidades guarda-roupa são reunidas enquanto dura o espetáculo e prontamente desfeitas quando os espectadores apanham os seus casacos nos cabides. Suas vantagens em relação à "coisa genuína" são precisamente a curta duração de seu ciclo de vida e a precariedade do compromisso necessário para ingressar nelas e (embora por breve tempo) aproveitá-las". (BAUMAN, Zygmunt. Identidade: entrevista a Benedetto Vecchi. Tradução de Carlos Alberto Medeiros. Rio de Janeiro: Jorge Zahar, 2005. p. 37).

27 “(...) "comunidades de guarda-casacos" (...). São comunidades fantasmas, comunidades $a d$ hoc, carnavalescas - os tipos de comunidades às quais alguém acha que está se juntando simplesmente por se encontrar onde outros se encontram, ou por portar distintivos ou outros símbolos de intenções, estilo ou gosto comuns; e comunidades com prazos fixos (ou plenos menos reconhecidos como temporários), das quais se "debanda" quando o grupo se dispersa embora sendo livre para sair disso, a qualquer momento em que o interesse comece a diminuir" (BAUMAN, Zygmunt. Vida para consumo: transformação das pessoas em mercadoria. Tradução de Carlos Alberto Medeiros. Rio de Janeiro: Jorge Zahar, 2008. p. 143).

28 BAUMAN, Zygmunt. A sociedade individualizada: vidas contadas e histórias vividas. Tradução de José Gradel. Rio de Janeiro: Jorge Zahar, 2008. p. 8. 
Tais observações são de enorme relevância, já que é esse processo de plena transferência da determinação da identidade para a sociedade moderna ou para a comunidade líquido-moderna que, em última instância e guardadas as devidas diferenciações, dificulta nos dois momentos a implementação de um direito cosmopolita, distanciando ainda mais o ser humano de uma verdadeira conscientização como gênero, responsáveis que são pela colocação de entidades e fantasias entre o indivíduo e a sociedade presentes e a humanidade, ao focalizarem sempre nas desconformidades constantemente crescentes e reiteradas, negligenciando parecenças com a explicação de uma autopreservação fragmentária.

Ocorrem, simultaneamente, uma grande fragmentação, reduzindo "os laços sociais a um verniz superficial", ${ }^{29}$ e um enorme distanciamento do encontro da efetiva raiz do problema, afastando, nas palavras de Z. Bauman, a culpa das instituições e voltandoa para características individuais, processo que apenas culmina na ampliação de raiva contra a diferença ou na autocensura e autodepreciação, canalizando, possivelmente, tal energia de neutralização para manifestações de violência dirigidas ao Outro e/ou a Si, em comportamentos reivindicatórios de emancipação concomitantes a desesperos pelo encontro de confortos do compartilhamento.

A problemática da Ambivalência, decorrente do que fora mencionado, é suscitada pelas preliminares fundamentais à implantação ou, ao menos, à decisão por um caminhar almejante dos fundamentos de um direito cosmopolita - noção que intenta, em linhas gerais, como já reiteradamente apontado, tomar a Humanidade, o Gênero Humano como protagonista de um conjunto de normas de convivência referente a cidadãos do mundo, congregados no objetivo da Paz. Entretanto, a universalidade da cidadania é acusada, freqüentemente, de assumir o papel de antagonizar o Pluralismo Humano e suas Ambivalências, preconiza-se, em substituição a um direito cosmopolita delatado como opressor, a convivência meramente indiferente, dita, na realidade, tolerante - em sua versão fraca -; sabendo-a capaz de lidar com a coexistência apenas até o momento em que se fizer necessário o diálogo. A inexistência de sólidos pontos de contato comuns entre os Estados, as nações, sociedades ou comunidades - quaisquer referenciais para esse mundo de indiferença - torna a situação fronteiriça à armamentização do conflito, em uma incrementação da sensação de ameaça constante.

Considerando a moldura, amplamente vendida e sucintamente apresentada de uma coexistência insegura e descomprometida com a responsabilidade por si e pelo Outro, quer-se recomendar no presente trabalho exatamente o oposto do entendimento míope que se defende comumente: a diferença deve ser cristalizada e preservada como se peça viva de museu fosse: intocável, irrepreensível, longinquamente admirada quando

29 BAUMAN, Zygmunt. Modernidade e ambivalência. Tradução de Marcus Penchel. Rio de Janeiro: Jorge Zahar, 1999. p. 292. 
hermeticamente situada em ambiente artificialmente arquitetado em seção especial, harmonicamente a seu conjunto de pertencimento. O pluralismo pode, segundo termos de Z. Bauman, melhorar a existência compartilhada e culminar paulatinamente na construção de um direito gerado através da comunicação efetiva dos variantes culturais por meio de um processo político humano. Nesse diapasão, considera-se à universalidade da cidadania inserida em uma conjuntura de solidariedade cosmopolita como denso desafio exatamente a questão da azáfama da Ambivalência em prol da congregação humana. Para a viabilização desse cenário cosmopolita solidário, deve cada um desenvolver disposição para a defesa ativa da diferença alheia, como forma de preservação da possibilidade da própria peculiaridade humana.

Não se está aqui negando as dificuldades envolvidas no estabelecimento de uma construção de convivência humana em um contexto no qual a comodificação preponderante é responsável por categorizar os verdadeiros elementos do sucesso e, portanto, da felicidade. ${ }^{30}$ Reconhece-se o fato de que contrariar a hegemônica compreensão de mundo pode ser visualizado como comprovação de fraqueza ou ingenuidade em relação à forma pela qual, efetivamente, movimenta-se o mundo, no entanto, o intuito desse trabalho é exatamente o de negar essa concepção, o de inverter a polaridade majoritária e amplamente difundida, amplificada como suposição tácita inquebrantável, e afirmar que é possível construir a convivência humana sustentada pela solidariedade e reforçada pelo conhecimento prático da comunicação entre diferentes, por meio de instâncias coletivas de diálogo: instâncias políticas. Compreende-se que o desengajamento consiste, na realidade, na descrença em relação à potencialidade humana de existir como ser humano, de cuja qualificação essencial, segundo preconiza a sabedoria aristotélica, é a politização de seu comportamento, derivada de um autocomprometimento, no tocante à instância política, menos limitada do que cada indivíduo condicionado, situado, restrito, pois a sabe múltipla.

No direito cosmopolita aqui preconizado:

Minha ligação com o estranho é revelada como
responsabilidade, não apenas como neutralidade indiferente
ou mesmo aceitação cognitiva da similaridade de condição
(...). É revelada, em outras palavras, como comunidade de
destino, não mera semelhança de fado. A uma sina comum
bastaria a tolerância mútua; o destino comum requer
solidariedade. O direito do Outro à sua estranheza é a única
maneira pela qual meu próprio direito pode expressar-

30 “As condições da sociedade individualizada são inóspitas à ação solidária; elas militam contra a visão da floresta por trás das árvores. (...). A sociedade individualizada caracteriza-se pelo afrouxamento dos laços sociais, esse alicerce da ação solidária. Também é notável por sua resistência a uma solidariedade que poderia tornar esses laços duráveis - e seguros". (BAUMAN, Zygmunt. O mal-estar na Pós-modernidade... cit., p. 32). 
se, estabelecer-se e defender-se. é pelo direito do Outro que meu direito se coloca. "Ser responsável pelo Outro" e "ser responsável por si mesmo" vêm a ser a mesma coisa. Escolher as duas coisas e escolhê-las como uma, uma só atitude indivisível, não como duas instâncias correlatas mas separadas, é o significado de reformular a contingência de sina em destino (...) só não podem dizer que ela decorre de uma regra ou comando (...). ${ }^{31}$

As diretrizes aduzidas são impossibilitadas, manifestamente, com a manutenção e o crescimento da categoria dos vulneráveis sociais em inúmeros aspectos. A Ambivalência, pressuposta a diferença, é nesse momento discutida e apontada, já que responsável pela justificação de relações de heteronomia, subalternização, humilhação; situação que, em última instância, revela a insegurança da convivência, o medo, inúmeras vezes salientado, da destruição dos predominantes parâmetros sociais de compreensão do mundo e da catástrofe pessoal, considerando que a mutabilidade dos moldes aceitáveis culmina na possibilidade efetiva de transformar-se em alvo a qualquer momento. É o temor do que está subjacente ao explícito que sustenta o ódio violento a outros seres humanos, tomados como simples sujeiras, desafiadores que são, como ambivalentes à padronização social, a cujo reforço são empregados esforços estonteantes, da segurança da vida cotidiana, são perigosos, questionadores ao simplesmente existir Esse fenômeno, salientase, está presente nas conjunturas aqui compreendidos como sólida e líquida modernidade, a modificação opera-se em função dos distintos referenciais de reconhecimento e adequação sociais, no entanto, o poder de excluir não se limita à manifestação em um único momento histórico, sendo inclusive apontado como um fator compartilhado e determinante no distanciamento do caminhar cosmopolita.

(...), podemos deduzir que o interesse pela pureza, e o associado interesse pela "higiene" (isto é, manter a sujeira longe) tem uma relação mais do que acidental com a fragilidade da ordem; com uma situação em que sentimos não poder confiar na ordem cuidando dela própria (...) Se a "sujeira" é um elemento que desafia o propósito dos esforços de organização, e a sujeira automática, autolocomotora e autocondutora é um elemento que desafia a própria possibilidade de esforços eficientes, então o estranho é a verdadeira síntese desta última. Não é de surpreender que as pessoas do lugar, em toda a parte e em todos os tempos, em seus frenéticos esforços de separar, confinar, exilar ou destruir os estranhos, comparassem os objetos das suas diligências aos animais nocivos e às bactérias. Não é de

31 BAUMAN, Zygmunt. Modernidade e ambivalência. Tradução de Marcus Penchel. Rio de Janeiro: Jorge Zahar, 1999. p. 249. 
surpreender, tampouco, que comparassem o significado de sua ação a rotinas higiênicas; combateram os "estranhos", convencidos de que protegiam a saúde contra os portadores de doença. ${ }^{32}$

A vulnerabilização, o rebaixamento, a heterofobia apenas tornam o ambiente de diálogo mais rechaçado ou insincero e, portanto, tendente ao caos ou à estagnação. Essa mortificação a uma condição inferior ou externa a uma coletividade na qual "se está fisicamente" envolve a questão da compreensão da identidade, elemento responsável que é pela caracterização do modus do relacionamento indivíduo-coletivo. Um encaminhamento verdadeiro para a compreensão das subjacências irrenunciáveis de um bem-sucedido direito cosmopolita necessariamente implica a análise da questão da identidade, problemática, já que sua relação com a Humanidade como gênero encontrase inserida em um contexto de instabilidade, ressaltados que estão os meios satisfação pessoal e imediata diante da fragilidade da condição social, em detrimento, portanto, da autoidentificação como pertencimento duradouro e empenhado.

A questão da Identidade

A identidade - entendendo seus efeitos potencializados, nos processos de liquefação atuais, pela limitação do conhecer-se a um reconhecimento pessoal efêmero e socialmente desamparado - constitui-se um fator essencial na estratificação, na estigmatização, relacionado, por conseguinte, à Ambivalência dos deslocados, ou melhor, dos não-alocados, pertencentes a lugar nenhum, em relação ao modelo social preponderante; a existência e presença desses seres falhos é utilizada como instrumento de manutenção do medo do questionamento do estado de coisas.

A Idade Moderna foi responsável, juntamente com a preconização do Estado e da nação como categorias sólidas, alicerces do sistema social, pela construção da noção de identidade, apresentando às pessoas a sua própria individualidade e tornando viável a indagação sobre quem ser. Além da introdução da identificação pessoal aos indivíduos - realizando imenso esforço de redução do denominado poder de vizinhança, ao qual se atribuía uma gigantesca força centrífuga dos seres humanos, impassíveis de serem além ou fora do que se apresentava sua comunidade ou do papel que a ele era atribuído desde o berço -, o questionamento do quem de si mesmo foi atrelado, à época, aos demais conceitos básicos da civilização moderna - emancipação, tempo/espaço, trabalho e comunidade -, sustentava-se na medida e na forma em que e com que o faziam as

32 BAUMAN, Zygmunt. O mal-estar na pós-modernidade. Tradução de Mauro Gama e Cláudia Martinelli Gama. Rio de Janeiro: Jorge Zahar, 1998. p. 15-19. 
demais categorias. Enfim, a individualidade passou a ter como determinantes inexoráveis as mais sólidas noções de embasamento da modernidade sólida, mas a liquefação desse complexo de rijas idéias culminou na percepção líquido-moderna da ilusão da identidade, da contingência e da ambivalência de sua aquisição, já que, valoriza-se o movimento constante e sua velocidade, preconizam-se identidades como mantos leves, despojáveis a qualquer momento em que não mais haja satisfação em portá-lo e estamos perdendo a capacidade, ou mesmo a querência de nos relacionar com comunidades verdadeiras e pessoas reais. A segurança, no momento, é entendida como a adesão à Compromissofobia: a inexistência de projetos de longo prazo, para o qual se dedicam as forças de uma vida, além do aumento em quantidade das oportunidades de experimentação, diminuem as possibilidades de frustração, no entanto, relacionamentos humanos superficiais, incapazes de construírem diálogos, baseados apenas em um presente contínuo que, portanto, nunca afeta um futuro que não se sabe e nem se quer saber, dificultam o entendimento de nós mesmos. A mudança radical do cenário altera o modo do ser humano estar no mundo e estar como Humano, trazendo implicações ao entendimento de gênero.

O esvaziamento da cidadania e a erosão dos elementos responsáveis pelo entendimento sólido-moderno do mundo forçam os indivíduos a encontrarem formas de reconhecimento social outras, brutalmente hoje associadas aos mecanismos de reprodução da sociedade de consumo, gerando, em decorrência, de uma sangrenta divisão social pela incapacidade de comodificação, a subclasse de consumidores falhos, impuros, presos, já que a identidade é reconhecida em sua liberdade mercadológica, ou seja, em sua possibilidade de atuação conforme os múltiplos direcionamentos do consumo. Essa pobre ambivalência redundante caracteriza-se, hodiernamente, como Vulnerabilizados Sociais, que, em grande medida, possuem relação com os arrivistas e párias sólido-modernos, considerando que muitos dos detentores do poder de hierarquização nos moldes precedentes deixaram herdeiros na mesma posição. A existência utilitária desse complexo de seres e o auxílio que dão e deram à manutenção do sistema de poder, representando os perigos reais da não-submissão aos modelos propugnados, desafia a concepção cosmopolita de superação da intolerância no tocante à diferença. ${ }^{33}$

A Vulnerabilidade e a Necessidade de Superação em direção ao Direito Cosmopolita

Na modernidade sólida, poder-se-ia agrupar duas principais categorias de vulneráveis sociais: os arrivistas e os párias, ambas relacionadas à situação de

33 "O real sentido do cosmopolitismo se dá a partir da ruptura da condição de subalternidade por aquele que é feito refém dela, ou seja, por quem é feito subalterno em políticas internacionais". (BITTAR, Eduardo Carlos Bianca. $O$ direito na pós-modernidade... cit., p. 356). 
pertencimento ao conjunto social, de identidade nacional, de atrelamento a determinado povo e território. Os arrivistas são seres humanos em busca frenética por identidade, por uma forma de auto-identificação, pois se vêem na situação de deslocamento freqüente, em lugares onde aspiram a residir, porém não sua aspiração é acompanhada pela nãopermissão de residência: vivem em constante ameaça de deportação, em um cenário, portanto, de imensa instabilidade. Um arrivista nunca supera a marca de sua procedência, já que se exige dele que porte uma demonstração de sua condição. Os párias estão em uma situação peculiar de não pertencer a classe alguma até o advento da modernidadesólida, quando foi declarada a inexistência de intocáveis ao ser instaurado o dinamismo interclassista, um dos fatores de reivindicação burguesa anti-absolutista, no entanto, devese completar a afirmação, dizendo que os párias podiam ser alçados apenas à condição de arrivista e, portanto, compartilharem da imensa instabilidade de que é dotada a mencionada condição.

Os grupos analisados são, ambos, compreendidos como indesejáveis em decorrência de dois motivos fundamentais: em primeiro lugar, recordam àqueles adaptados socialmente das convenções artificiais a que foram conduzidos a aderir, possibilitando um aumento no nível de tensão, insatisfação e frustração com as progressistas estruturas prometidas quando formação da civilização moderna; em segundo, acrescenta-se a existência da estigmatização do diferente como irrenunciável ao modelo sólido-moderno cujos universalismos sabem-se seus elementos de sustentação e afirmação.

Ligado umbilicalmente à questão da Identidade é denominado por Z Bauman como a produção de lixo humano, o processo de ampliação da subclasse social é, atualmente, um fenômeno transnacional e de caráter excludente, mais do que exploratório, como na sólida modernidade, pois a importância que adquiriu a identidade associada ao fenômeno da privatização da vida, abandonando cada qual à utilização de seus próprios instrumentos, relaciona-se com o poder de exclusão, da retirada de certos indivíduos inadequados da lista dos que, ao menos, são considerados, impossibilitando sumariamente qualquer possibilidade de alcance de um rosto socialmente notado.

A vulnerabilidade cresce com o incremento do grupo heterogêneo de pessoas cujo elemento compartilhado sabe-se a exclusão, a caracterização como subclasse ${ }^{34}$,

34 "O termo "subclasse" (...) pertence a uma imagem de sociedade completamente distinta: implica uma sociedade que é tudo menos hospitaleira e atenciosa com todos, uma sociedade atenta, em vez disso, ao lembrete de Carl Schmitt de que o traço definidor da soberania é a prerrogativa de eximir, excluir e colocar de lado uma categoria de pessoas às quais a lei é aplicada mediante a negação ou revogação de sua aplicação. "Subclasse" evoca a imagem de um agregado de pessoas que foram declaradas fora dos limites em relação a todas as classes e à própria hierarquia de classes, com poucas chances e nenhuma necessidade de readmissão: pessoas sem um papel, que não dão uma contribuição útil às vidas dos demais, e em princípio além da redenção. Pessoas que, numa sociedade dividida em classes, não constituem nenhuma classe própria, mas se alimentam das essências vitais de todas as outras, erodindo, desse modo, a ordem da sociedade baseada em 
reconhecendo a impossibilidade de se determinar uma totalidade integrada, já que todos os rejeitados, na modernidade líquida, são colocados nesse limpo social de desconsideração. $\mathrm{Na}$ realidade, como já mencionado de forma sutil, há uma utilidade aos ditos dejetos sociais: a de sustentar as incertezas, as ambigüidades dos privilegiados turistas, mostrando publicamente aquilo de que sempre se distanciam, ou seja, "são suas privações gritantes demais que reduzem as preocupações das pessoas com as inconveniências marginais". 35 São os denominados Vagabundos ou Consumidores Falhos, são estes os alter egos dos turistas; categoria que pode ser compreendida como:

Ser um alter ego significa servir como um depósito de entulho dentro do qual todas as premonições inefáveis, os medos inexpressos, as culpas e autocensuras secretas, demasiadamente terríveis para serem lembrados, se despejam; ser um alter ego significa servir como pública exposição do mais íntimo privado, como um demônio interior a ser publicamente exorcizado, uma efígie em que tudo o que não pode ser suprimido pode ser queimado. $\mathrm{O}$ alter ego é o escuro e sinistro fundo contra o qual o eu purificado pode brilhar (...). Os vagabundos são a caricatura que revela a fealdade escondida sob a beleza da maquiagem. Sua presença é enfadonha e enraivecedora. ${ }^{36}$

\section{Apontamentos finais - conclusão}

$\mathrm{O}$ intuito do presente trabalho foi, partindo do contexto líquido-moderno e da peculiaridade com que se trata a Ambivalência, aquele de apresentar algumas reflexões acerca, essencialmente, da complexidade da convivência humana e sua formulação quando da arquitetagem de um direito verdadeiramente cosmopolita e, por conseguinte, sustentado pela idéia de Humanidade como gênero cujas diferenças e ambigüidades intrínsecas seriam identificadas, reconhecidas, aceitas, toleradas e defendidas, através de comportamentos solidários de abertura ao diálogo e reforço da coexistência compartilhada mediante uma comunicação não-violenta, de escuta e colaboração respeitosas e convergentes, portanto. Há inúmeros desafios a serem sobrepujados, uma vez que, educados em heranças sólido-modernas, estamos habituados cegamente a ansiar por necessidades e buscar desesperadamente a segurança dos iguais, do previsível, do planejado, amedrontados que somos da exclusão, da inadequação, do estranhamento.

Entretanto, a solidariedade é possível, admitindo o ser humano como ser social, mas exige de cada uma atitude de enfrentamento da própria autenticidade,

classes. (...)." (BAUMAN, Zygmunt. Vida para Consumo... cit., p.156).

35 Id. O mal-estar na pós-modernidade... cit., p. 120.

36 Id. Ibid., 119. 
composta de sonhos, angústias, medos, planos, incertezas, paixões, ao contrário, portanto, da solução ilusória preconizada pela sociedade do consumo, colocando entre nós e nosso próprio eu, muralhas de adornos mercadológicos. O resultado é a abdicação de nós mesmos pelo desconhecimento de outra subjetividade, que não aquela socialmente aprovada e o conseqüente desenvolvimento de uma enormidade de inimigos, já que projetada nos demais a insatisfação consigo mesmo, com o círculo aparentemente inexorável de normalidades repetidas.

Busquemos a nós mesmos por detrás dos papéis sociais com os quais nos vestimos, desmistificando o que é compreendido como inadequado para destemer a doação de si e o recebimento do próximo em canais comunicativos. Freqüentemente, no campo de batalha ou no cumprimento das perpétuas penas impostas nas modernidades sólida ou líquida, o indivíduo acredita estar sendo forte, quando, na verdade, demonstra grande fraqueza ou falta de coragem de assumir-se ser humano. Na questão da vulnerabilidade está implicada a necessidade de dominação e de imposição de subalternidade de uns sobre os outros. Preconiza-se a imprescindibilidade da convivência humana verdadeira, compartilhada, para o próprio conhecimento de si mesmo, mediante reflexões e exercícios de análise do mundo vivido, efetivamente convivido, e não apenas sobrevivido.

O papel da Filosofia na conscientização do ser humano em relação às suas potencialidades faz culminar reflexões de que a busca pela nossa identidade demanda uma autodescoberta, uma corajosa autolibertação, que, exatamente por decorrente do compartilhamento de perspectivas, solidária, reforçadora do outro como continuidade de si. O Direito, como importante estrutura de organização social formal, não pode ser conivente com qualquer idéia diferente ao cosmopolitismo em sua vertente real, efetiva. A concepção de base apontada no presente texto sustenta o sucesso do caminhar em direção a um Direito Cosmopolita, capaz de reconhecer e se solidarizar com a diferença do Outro, que, na realidade, não é muito distinto, já que todos Seres Humanos.

São Paulo, junho de 2009.

\section{Referências}

BAUMAN, Zygmunt. A arte da vida. Tradução de Carlos Alberto Medeiros. Rio de Janeiro: Jorge Zahar, 2009.

Comunidade: a lusca por segurança no mundo atual. Tradução de Plínio Dentzien. Rio de Janeiro: Jorge Zahar, 2003.

. Globalização: as conseqüências humanas. Tradução de Marcus Penchel. Rio de Janeiro: Jorge Zahar, 1999. 
. Identidade: entrevista a Benedetto Vecchi. Tradução de Carlos Alberto Medeiros. Rio de Janeiro: Jorge Zahar, 2005.

. Medo líquido. Tradução de Carlos Alberto Medeiros. Rio de Janeiro: Jorge Zahar, 2008.

. Modernidade e ambivalência. Tradução de Marcus Penchel. Rio de Janeiro: Jorge Zahar, 1999.

. Modernidade e Holocausto. Tradução de Marcus Penchel. Rio de Janeiro: Jorge Zahar, 1998.

. Modernidade líquida. Tradução de Plínio Dentzien. Rio de Janeiro: Jorge Zahar, 2001.

. O mal-estar na pós-modernidade. Tradução de Mauro Gama e Cláudia Martinelli Gama.

Rio de Janeiro: Jorge Zahar, 1998.

. A sociedade individualizada: vidas contadas e histórias vividas. Tradução de José Gradel. Rio de Janeiro: Jorge Zahar, 2008.

- Vida para consumo: a transformação das pessoas em mercadoria. Tradução de Carlos Alberto Medeiros. Rio de Janeiro: Jorge Zahar, 2008.

BITTAR, Eduardo Carlos Bianca. O direito na pós-modernidade. Rio de Janeiro: Forense Universitária, 2005.

. Ética, Educação, Cidadania e Direitos Humanos: estudos filosóficos entre cosmopolitismo e responsabilidade social. Barueri: Manole, 2004.

FELIPPE, Marcio Sotello. Razão jurídica e dignidade humana. São Paulo: Max Limonad, 1996.

GIRARD, René. A violência e o sagrado. Tradução de Martha Conceição Gambini. São Paulo: Editora da Universidade Estadual Paulista, 1990.

KAFKA, Franz. A metamorfose. Tradução de Modesto Carone. São Paulo: Companhia das Letras, 1997.

KANT, Immanuel. À paz perpétua e outros opúsculos. Tradução de Artur Mourão. Rio de Janeiro: Edições 70, 1990. 